\title{
An outbreak of a penicillin-sensitive strain of gonorrhoea in Sydney men
}

J H Rowbottom, J W Tapsall, D C Plummer, N J Bodsworth, M A MacDonald, I W Chambers, J M Kaldor

\begin{abstract}
Objective-To describe an outbreak of gonorrhoea caused by penicillin sensitive Wild type 1B2-Wt/1B2(FS), in homosexual men in Sydney.

Design and setting-The study sample comprised all gonococcal isolates referred to the Gonococcal Reference Laboratory (GRL), New South Wales, Australia between 1 January 1990 and 30 June 1992. Demographic data on Wt/1B2(FS) were sought by review of all request forms accompanying specimens to the GRL. Detailed review was undertaken of the clinical records of all men with gonorrhoea which had been differentiated by auxotype and serotype (A/S) from two large STD clinics in Sydney.
\end{abstract}

Measurements and main results-The first isolation of $\mathrm{Wt} / 1 \mathrm{~B} 2$ (FS) was made in April 1990 and by the end of July 1992, 140 such isolates were identified in 131 patients. The male:female ratio was 130:1 suggesting male homosexual transmission, which was confirmed in 55 of 57 evaluable cases. There was a higher proportion of pharyngeal and anal infections among Wt/1B2(FS) isolates compared with all other male gonorrhoea. Demographic information showed that $60 \%$ of men with Wt/1B2(FS) were under the age of 30 , and $80 \%$ lived in Central or Eastern Sydney.

National Centre in HIV Epidemiology and Clinical Research, University of New South Wales, Sydney, Australia

J H Rowbottom

M A MacDonald

J M Kaldor

National Centre for

Epidemiology and

Population Health,

Canberra, Australia

J H Rowbottom

Prince of Wales

Hospital, Randwick,

Sydney, Australia

JW Tapsall

Sydney Sexual Health

Centre, Sydney,

Australia

D C Plummer

N J Bodsworth

Taylor Square Clinic,

Darlinghurst, Sydney,

Australia

N J Bodsworth

Douglass Laboratories

I W Chambers

Accepted for publication

18 January 1994
Conclusions-An outbreak of a penicillin sensitive strain of gonorrhoea has occurred in Sydney, primarily among gay men living in the inner city. The extent to which the outbreak represents an increase in the risk of HIV transmission is unclear.

(Genitourin Med 1994;70:196-199)

\section{Introduction}

The incidence of gonorrhoea in homosexual men decreased significantly during the early 1980s in Australia, ${ }^{1-6}$ the USA ${ }^{7}$ and Europe. ${ }^{89}$ This decrease was largely attributed to changes in sexual practice in response to the HIV epidemic. ${ }^{7}$ Several recent reports of gonorrhoea among homosexual men in Australia and other countries ${ }^{10-13}$ have suggested that there has been a reversal of this trend in the late 1980 s.

The existence of distinct, stable subtypes of Neisseria gonorrhoeae, defined by auxotype and serotype (A/S) classes, ${ }^{14}$ provides a basis for studying incidence patterns at a more detailed level. In the USA, there are clear associations between these classes and various geographic and social factors. ${ }^{15}$

In Sydney the number of gonococcal isolates which were fully sensitive to penicillin (as defined by a minimum inhibition concentration $\leqslant 0.03 \mathrm{mg} / \mathrm{L}$ ) increased from $7.5 \%$ of all isolates in $1989-90$ to $30 \%$ in $1991-92$, reversing a decreasing trend over the previous 10 years. ${ }^{16}$ One A/S class in particular, Wild type $1 \mathrm{~B} 2(\mathrm{Wt} / 1 \mathrm{~B} 2(\mathrm{FS}))$ was noted to occur in the penicillin sensitive group with increasing frequency in 1991-92. ${ }^{17}$ This paper describes the introduction of $\mathrm{Wt} / 1 \mathrm{~B} 2(\mathrm{FS})$ to Sydney, using data from the New South Wales Gonococcal Reference Laboratory, combined with more detailed information from two large STD clinics.

\section{Methods}

The NSW Gonococcal Reference Laboratory (GRL) is the coordinating laboratory for the Australian Gonococcal Surveillance Program (AGSP), established in 1981 to monitor gonococcal antibiotic sensitivities throughout Australia using standardised techniques. ${ }^{2}$ Isolates are referred from public and private laboratories in Sydney to the NSW GRL for sensitivity testing and subtyping.

A/S determination has been performed for all gonococcal isolates submitted in Sydney since 1984, using methodology previously described. ${ }^{14} 18$ The nomenclature of Knapp et $a l^{14}$ has been used since 1987 .

We reviewed all isolates of gonorrhoea received at the reference laboratory from the beginning of January 1990 to the end of June 1992. A computerised database is maintained by the reference laboratory and contains information on each isolate, including quarter of isolation, gender, the site from which the isolate was obtained and antibiotic sensitivities as well as the auxotype and serotype.

Information on age and postcode was obtained for isolates of $\mathrm{Wt} / 1 \mathrm{~B} 2$ (FS) from the request forms which accompanied the specimens to the referring laboratory. Sexual preference was sought by call back to patients' practitioners or by review of case notes.

Because the reference laboratory did not specifically seek information on sexual preference and demographic characteristics, additional data collection and analysis was undertaken on all cases of gonorrhoea in men referred from two major STD clinics, Sydney 
Sexual Health Centre and Taylor Square Private Clinic.

Statistical analysis in which comparison of $\mathrm{Wt} / 1 \mathrm{~B} 2$ (FS) with all other strains of gonorrhoea referred to the GRL was made with regard to quarter of referral, gender and site of isolate. Comparisons were also made between Wt/1B2(FS), other penicillin-sensitive isolates and all other isolates with regard to quarter and site. For the two STD clinics, a separate comparison with regard to demographic data and sexual preference was made between men with $\mathrm{W} t / 1 \mathrm{~B} 2$ (FS) and men with all other strains of gonorrhoea. Place of residence was classified as Eastern and Central Sydney, or other, because Eastern and Central Sydney are recognised as being focal points for the Sydney gay community.

Groups were compared using standard chi square methods ${ }^{19}$ and trends over time were compared using Generalised Linear Interactive Modelling (GLIM). ${ }^{20}$

\section{Results}

During the two and a half year study period, 1070 isolates of gonorrhoea were referred to the NSW GRL from Sydney laboratories. Of this total, 140 isolates were the $\mathrm{Wt} / 1 \mathrm{~B} 2$ (FS)

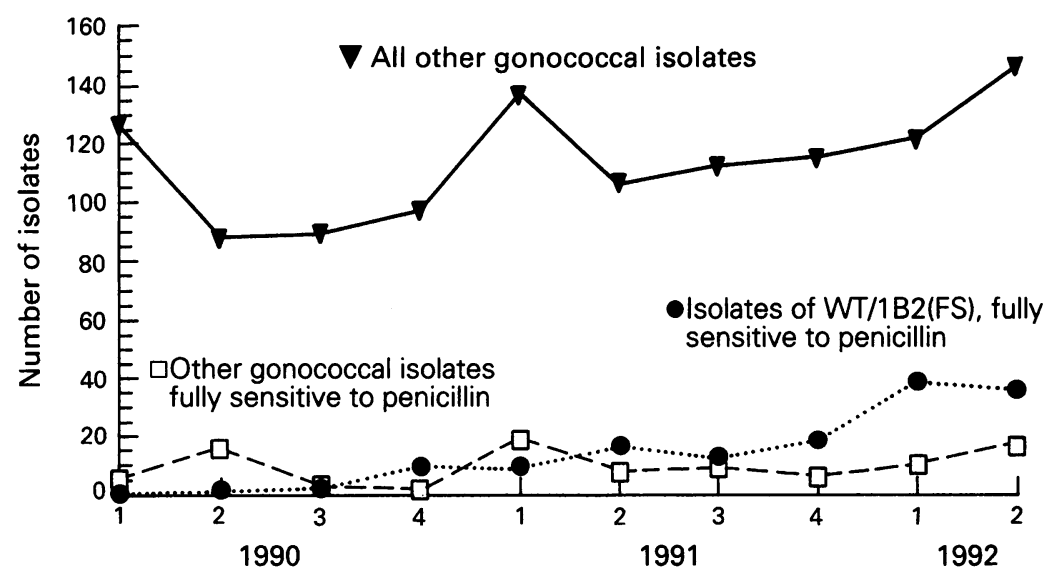

Fig Isolation of gonococci by quarter, 1990-1992, Sydney.

Table 1 Isolates of Wt/1B2(FS), other gonococci fully sensitive to penicillin and all other gonococci by sex and site, Sydney 1 fanuary 1990-30 fune 1992

\begin{tabular}{lccc}
\hline Site of isolation & Wt1B2(FS) & $\begin{array}{l}\text { Other peniccillin } \\
\text { sensitive gonococci }\end{array}$ & $\begin{array}{c}\text { All other } \\
\text { gonococci }\end{array}$ \\
\hline Male: & & & \\
Urethra & $106(75.7 \%)$ & $74(74 \cdot 8 \%)$ & $497(59 \cdot 8 \%)$ \\
Pharynx & $8(5 \cdot 7 \%)$ & $2(2 \cdot 0 \%)$ & $4(0.5 \%)$ \\
Anorectum & $24(17 \cdot 2 \%)$ & $10(10 \cdot 1 \%)$ & $13(1 \cdot 6 \%)$ \\
Total male & $138(98.5 \%)$ & $86(86.9 \%)$ & $514(61.9 \%)$ \\
Female & $1(0.7 \%)$ & $13(13.1 \%)$ & $312(37.5 \%)$ \\
Other & $1(0 \cdot 7 \%)$ & $0(0 \cdot 0 \%)$ & $5(0.6 \%)$ \\
Total & $140(100 \%)$ & $99(100 \%)$ & $831(100 \%)$ \\
\hline
\end{tabular}

strain, representing $13 \%$ of the total number of isolates and $60 \%(140 / 239)$ of the isolates which were fully sensitive to penicillin. These 239 fully sensitive isolates comprised 31 different $\mathrm{A} / \mathrm{S}$ classes. Other strains fully sensitive to penicillin occurred in low numbers $(\leqslant 7)$ with the exception of $\mathrm{Wt} / 1 \mathrm{~B} 6$ which made up 37 of $239(16 \%)$ of the fully penicillin sensitive isolates.

Wt/1B2(FS) was first isolated in Sydney in April 1990. The figure demonstrates the gradually increasing incidence of $\mathrm{Wt} / 1 \mathrm{~B} 2(\mathrm{FS})$ during the study period to reach a peak of 73 isolates ( $46 \%$ of all gonococcal isolates) in the first half of 1992 . This increase was significant, ( $p$ value for trend $=<0.001$ ) as was the increase in the incidence of all other gonorrhoea ( $p$ value for trend $=<0.01$ ) but the increase for other penicillin sensitive gonorrhoea was not significant ( $p$ value for trend $=0 \cdot 14)$.

The 140 isolates of $\mathrm{Wt} / 1 \mathrm{~B} 2$ (FS) came from 131 individuals of whom 130 were men and one was a woman (table 1). Although $32 \%$ of all gonococcal isolates were from women, only one $(0.7 \%) \mathrm{Wt} / 1 \mathrm{~B} 2(\mathrm{FS})$ isolate was from a female patient. In males, a higher proportion of $\mathrm{Wt} / 1 \mathrm{~B} 2(\mathrm{FS})$ were pharyngeal or anorectal than for other strains $(p<0.05)$.

Mean age for the 91 men for whom age was available was $28 \cdot 5,(S D=5 \cdot 9$, range $20-34$ years). Sixty percent were under the age of 30 years. For the 84 men whose postcode of residence was known, $80 \%$ lived in Eastern or Central Sydney, and all except five of the remainder were from Sydney. Information on sexual preference was available for $57(44 \%)$ of the men with $\mathrm{Wt} / 1 \mathrm{~B} 2(\mathrm{FS})$. Of these 57 men, $55(96.5 \%)$ were reported as homosexual or bisexual.

One third of all isolates of $\mathrm{Wt} / 1 \mathrm{~B} 2(\mathrm{FS})$ were from people who attended either Sydney Sexual Health Centre or Taylor Square Private Clinic. Wt/1B2(FS) was more frequent among men with gonorrhoea who attended Taylor Square Private Clinic (40\% of cases) than men with gonorrhoea attending Sydney Sexual Health Centre (13\% of cases). $\mathrm{Wt} / 1 \mathrm{~B} 2(\mathrm{FS})$ was isolated from more than one site in nine men, and all except one attended either of the two STD clinics.

Among males diagnosed with gonorrhoea at the two STD clinics (table 2) Wt/1B2(FS) was more likely than other gonococcal strains to be isolated from the anorectum $(28.6 \%$ versus $14 \% p<0.05$ ). However, a large proportion of males with gonorrhoea attending these two clinics were homosexual: restricting this analysis to homosexual males, there was no significant difference in anatomical sites of isolation between $\mathrm{Wt} / 1 \mathrm{~B} 2 / \mathrm{FS}$ and all other strains of gonorrhoea.

The mean age at diagnosis of men with $\mathrm{Wt} / 1 \mathrm{~B} 2(\mathrm{FS})$ at the two clinics did not differ significantly from the age of men with other gonorrhoea (28.5 and 30.3 years respectively) at the two clinics. However, there was a significant difference in area of residence: more men with $\mathrm{Wt} / 1 \mathrm{~B} 2$ (FS) lived in Eastern or Central Sydney compared with all other areas. 
Table 2 Comparison of men with Wt/1B2(FS) gonorrhoea and men with other strains of gonorrhoea who attended Sydney Sexual Health Centre and Taylor Square Private Clinic: 1 Fanuary 1990-30 Fune 1992.

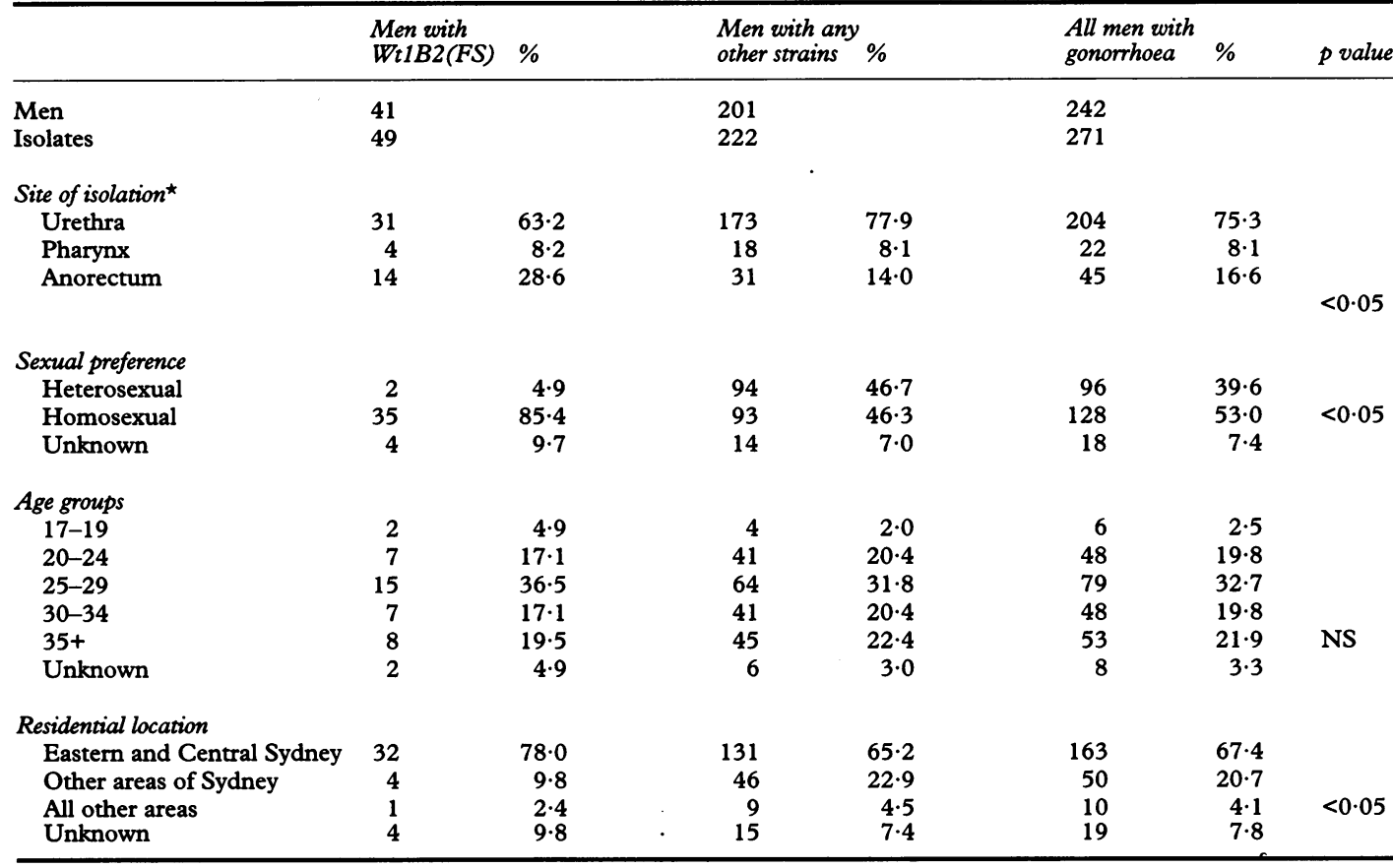

*Multiple infections in the same person are considered separately.

This difference was no longer significant when analysis was restricted to only homosexual men attending these clinics.

\section{Discussion}

We have described an outbreak of a strain of gonorrhoea which is fully sensitive to penicillin, $\mathrm{Wt} / 1 \mathrm{~B} 2$ (FS), occurring in Sydney from April 1990, and accounting for $21 \%$ of all isolates in Sydney by June 1992. Most cases appear to have resulted from sexual transmission between homosexual men living in Central and Eastern Sydney. This conclusion is supported by an overwhelming male to female ratio compared with other gonorrhoea cases; a propensity for non urethral sites in men, in particular the pharynx and anorectum, and a much higher proportion of $\mathrm{Wt} / \mathbf{1 B 2}$ (FS) cases in homosexual versus nonhomosexual men in two clinics where data on sexual behaviour were available for over $90 \%$ of patients.

There are several possible reasons for the apparent occurrence of a strain-specific gonorrhoea outbreak among homosexual men. Firstly, there may have been an increase in referrals from inner city clinics which gay men attend. However, there has been no change in the composition of the laboratories referring to the Gonococcal Reference Laboratory over the study period, and no evidence to suggest changes in their patterns of referral. A second possibility is that changes in diagnostic practice contributed to the outbreak, if for example, the extent of screening asymptomatic sites had increased among homosexual or bisexual men. There is no indication that any change of this kind took place, and if it had, it should not have affected the proportion of isolates represented by Wt/1B2(FS) over the study period. Thirdly, $\mathrm{Wt} / 1 \mathrm{~B} 2$ (FS) may have been introduced by a relatively small number of homosexual men, leading to a real increase in the incidence of the strain in a subgroup of relatively more sexually active homosexual men despite a general decrease in sexual activity among the wider population of homosexual men. ${ }^{21}$

Wt/1B2 gonococci have previously been associated with homosexual activity in men. ${ }^{22}$ In our study, sensitivity to penicillin was an additionally useful discriminator in strain differentiation, because most isolates from homosexual men are less sensitive to penicillin than those from heterosexual men. The increase in strains fully sensitive to penicillin was thus the first indication of the appearance of a new strain of gonococcus in Sydney. Epidemiological analysis which took into account both A/S typing and antibiotic sensitivity allowed a more detailed assessment of the outbreak.

The fact that patients with gonorrhoea attending the two large STD clinics were more likely to have multiple sites infected than patients attending other medical services suggests more intense screening of asymptomatic sites at STD clinics, but may simply be due to a greater proportion of homosexual men attending these practices and being diagnosed with gonorrhoea.

Transmission elsewhere in Australia has occurred, as indicated by reports from other centres where A/S typing is carried out, ${ }^{23}$ but did not appear in other centres until at least 12 months after the first detection of the strain in Sydney (Forsyth J, personal communication).

A real increase in the incidence of 
Wt/1B2(FS) among homosexual men may not be related to changes in sexual practice if the strain simply replaced other strains in the total pool of gonorrhoea circulating through sexual contact between men. Another possible explanation which does not involve any changes in sexual practice is that the biological affinity of this strain for non-urethral sites is greater than for other strains.

If there have been changes in sexual practices which led to the outbreak, there may be implications for the transmission of other STDs, including HIV. However, it is not possible to make a definite conclusion in this regard. Gonorrhoea can be transmitted by digital contact, oro-pharyngeal contact and other sexual practices which pose minimal risk for HIV transmission. The relationship between risk factors for gonococcal infection and the risk of HIV infection is complex, and it will be important in future studies both to clarify the sexual risk involved in transmission in specific cases at the time of gonococcal infection, and to link laboratory findings with accurate documentation of sexual behaviour.

Laboratory based data will continue to provide important information on trends in gonococcal disease and the potential risk of STD in general. A multi-disciplinary approach linking laboratory data to clinical information on sexual behaviour, symptomatology and screening practices will improve our understanding of the epidemiology of gonorrhoea, so that safe sexual practices will be better promoted among those groups most at risk.

1 Sherrard J, Forsyth JRL. Homosexually acquired gonorrhoea in Victoria, 1983-1991. Med ๆ Austr 1991;158: 450-3.

2 Australian Gonococcal Surveillance Programme. Penicillin sensitivity of gonococci in Australia: development of the Australian Gonococcal Surveillance Programme. Br $\mathcal{F}$ Venereal Dis 1984;60:226-30.
3 Australian Gonococcal Surveillance Programme. Changing patterns in gonococcal infection in Australia, 19811987. Med $\mathcal{F}$ Austr 1988;149:610-2.

4 Hart G. STD epidemiology in Australasia: syphilis and gonorrhoea. Venereology 1992;5:115-20.

5 Bradford DL. Sexually transmissible diseases: an overview. Australian Family Physician 1986;15:236-40.

6 Donovan B, Tindall B. Behaviour change in STD patients. In: Richmond $\mathrm{R}, \mathrm{W}$ akefield $\mathrm{D}$, eds. AIDS and Other Sexually Transmitted Diseases. Sydney: Harcourt Brace Sexually Transmitted Diseas

7 Handsfield HH, Schwabke J. Trends in sexually transmitted diseases in homosexually active men in King County, Washington, 1980-1990. Sexually Trans Dis 1990;17: 211-5.

8 Carne CA, Weller IV, Johnson AM, et al. Prevalence of antibodies to human immunodeficiency virus, gonorrhoea rates, and changed sexual behaviour in homosexual men in London. Lancet 1987;1:656-8.

9 Evans BG, Catchpole MA, Heptonstall J, et al. Sexually transmitted diseases and HIV-1 infection among homosexual men in England and Wales. BMf 1993;306: 426-8.

10 Forsyth JRL, Sherrard J, Traynor P. Resurgent gonorrhoea in homosexual men. Lancet 1990;336:878.

11 Riley VC. Resurgent gonorrhoea in homosexual men. Lancet 1991;337:183.

12 Waugh MA. Resurgent gonorrhoea in homosexual men. Lancet 1991;337:375.

13 Van den Hoek JAR, Van Griensven GJP, Coutinho RA. Increase in unsafe homosexual behaviour. Lancet 1991; 336:179-80.

14 Knapp JS, Tam MR, Nowinski RC, et al. Serological classification of Neisseria gonorrhoeae with use of monoclonal antibodies to outer membrane protein 1. F Infect Dis 1984;150:44-8.

15 Knapp JS, Holmes KK, Bonin P, et al. Epidemiology of gonorrhea: Distribution and temporal changes in auxotype/serovar classes of Neisseria gonorrhoeae. Sexually Trans Dis 1987;14:26-32.

16 Tapsall JW, Phillips EA, Schultz TR, Carr D, et al. The incidence of gonorrhoea and the antibiotic sensitivity of incidence of gonorrhoea and the antibiotic sensitivity of gonococci in

17 New South Wales Public Health Bulletin, New South Wales Health Department 1992:104.

18 La Scolea LJ, Young FE. Development of a defined minimal medium for the growth of Neisseria gonorrhoeae. Applied Microbiology 1974;28:70-6.

19 Armitage P, Berry EG. In: Statistical Methods in Medical Research. Oxford: Blackwell Scientific 1987 (2nd edition):371-80.

20 McCullagh P, Nelder JA. Generalised Linear Models. Great Britain: Chapman and Hall 1984.

21 Whitaker L, Renton AM. A theoretical problem of interpreting the recently reported increase in homosexual preting the recently reported increase in
gonorrhoea. Eur $\mathcal{F}$ Epidemiol 1992;8:187-91.

22 Serotyping Neisseria gonorrhoeae: a report of the Fourth International Workshop. Genitourin Med 1991;67:53-7.

23 Surveillance of Sexually Transmissible Diseases 1992. Department of Health and Community Services Victoria. 1993:19. 